\title{
Determination of Some Heavyweight Aggregate Half Value Layer Thickness Used for Radiation Shielding
}

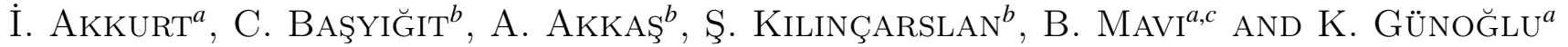 \\ ${ }^{a}$ Department of Physics, Science Faculty, Suleyman Demirel University, Isparta, Turkey \\ ${ }^{b}$ Department of Construction Education, Technical Education Faculty, Suleyman Demirel University, Isparta, Turkey \\ ${ }^{c}$ Faculty of Arts and Sciences, Dept. of Physics, Amasya University, Amasya, Turkey
}

\begin{abstract}
A radiation dose above the maximum permissible limit is very dangerous for human being. In radiation shielding, absorbent materials' properties must be well known. Heavyweight concrete is the most widely used in the world for this aim. The aggregate component of concrete plays an important role in improving concrete properties and this is effect of shielding properties of concrete. The thickness of any given material where $50 \%$ of the incident energy has been attenuated is known as the half-value layer. The half-value layer is expressed in units of distance $(\mathrm{mm}$ or $\mathrm{cm})$. Like the attenuation coefficient, it is photon energy dependent. Increase of the penetrating energy of a stream of photons will result in an increase in a material's half-value layer. In this study, half-value layer thickness of concrete containing limonite, siderite and barite at different ratios was investigated; for this purpose measurements have been obtained by a collimated beam of gamma ray from sources ${ }^{60} \mathrm{Co}$. The total linear attenuation coefficient $(\mu)$, half-value layer thickness is evaluated in this study.
\end{abstract}

PACS: $78.20 . \mathrm{Ci}$

\section{Introduction}

A radiation dose above the maximum permissible limit is very dangerous for human being. Radiation is a general term applied to nuclear particles or electromagnetic waves, which are a direct or indirect result of radioactive decay and fission. Gamma rays are attenuated in proportion to the atomic mass of the material. It is thus advantageous to make a gamma-ray shield of the most dense material economically feasible [1]. In radiation shielding, absorbent materials' properties must be well known. Shielding material must have high density, so high radiation attenuation coefficient, structural properties like high strength and it should be obtained or produced easily and at available low cost. In this respect, concrete is an excellent material for radiation shielding [2]. Heavyweight concrete is the most widely used in the world for this aim. The aggregate component of concrete that contains a mixture of many heavy elements plays an important role in improving concrete shielding properties and therefore has good shielding properties for the attenuation of photons and neutrons [3]. The purpose of radiation shielding is to limit radiation exposures to members of the public and employees to an acceptable level [4]. In case of special purpose of radiation shielding lead, steel, tungsten, and uranium can be used as heavyweight aggregates.

Mineral ores such as magnetite, siderite, barite and limonite etc. are more popular for producing heavyweight concrete because of economical factors. The use of heavy- weight concrete usually results in a reduction in the thickness of concrete required for radiation shielding [5]. The shielding effectiveness of concrete is to a large extent dependent on its density. If unit weight of concrete is increased, improvement of shielding properties is seen. The greater the density, the smaller the thickness of concrete required. The thickness of any given material where $50 \%$ of the incident energy has been attenuated is known as the half-value layer (HVL). The HVL is expressed in units of distance. Like the attenuation coefficient, it is photon energy dependent. Increase of the penetrating energy of a stream of photons will result in an increase in a material's HVL. In this study, half value layer thickness (HVLT) of concretes containing limonite, siderite and barite were investigated. For this purpose measurements have been obtained by a collimated beam of gamma ray from sources ${ }^{60} \mathrm{Co}$. The total linear attenuation coefficient $(\mu)$, HVLT is evaluated in this study.

\section{Materials and methods}

\subsection{Sample preparations}

Three different aggregates such as barite, limonite and siderite were used in the study. The maximum particle size of aggregate was kept constant at $16 \mathrm{~mm}$ in all mixtures. Fine and coarse aggregates were separated into two size fractions, $0-4 \mathrm{~mm}$ and $8-16 \mathrm{~mm}$, respectively.

Siderite. This mineral constitutes only a small proportion of the total world iron ore reserves. When pure, it contains $48 \%$ iron, but it is easily decomposed by heat 
(calcined) to hematite with $70 \%$ iron. Siderite is still a commercially important source of ore in some countries, e.g., Canada [6].

Barite. Barite ore includes $\mathrm{BaSO}_{4}$ which is a good photon radiation absorbent and is a heavyweight aggregate used in the concrete industry [7].

Limonite. Hydrated iron oxides containing, when pure, $60-63 \%$ iron. On heating, the water molecules are removed. It can occur as primary minerals or may be produced relatively near the surface as a result of weathering of the exposed ore. In low-grade silicate deposits, weathered outcrops of hydrated ore occur in which the iron content is greatly enriched. Such outcrops provided ore for the first steel industries [6].

Limonite and siderite aggregates that are used in concrete mixes were obtained from Hekimhan, Malatya, Turkey, barite aggregate was obtained from Şarkikaraağaç, Isparta, Turkey. Aggregates specific gravity were $3.5 \mathrm{~g} / \mathrm{cm}^{3}, 3.8 \mathrm{~g} / \mathrm{cm}^{3}$, and $4.0 \mathrm{~g} / \mathrm{cm}^{3}$, respectively. Portland cement produced according to the European Standards EN-197/1 was used as binder in all concrete mixtures. The cement was obtained at Goltas cement factory in Isparta, Turkey. Physical and mechanical properties and chemical analysis of cement are presented in Table I. Network water was used as mix water.

TABLE I

Physical and mechanical properties and chemical analysis of cement.

\begin{tabular}{l|c}
\hline \hline \multicolumn{1}{c|}{ Component } & $\%$ \\
\hline total $\mathrm{SiO}_{2}$ & 22.90 \\
$\mathrm{Al}_{2} \mathrm{O}_{3}$ & 5.32 \\
$\mathrm{Fe}_{2} \mathrm{O}_{3}$ & 3.63 \\
$\mathrm{CaO}$ & 55.83 \\
$\mathrm{MgO}$ & 1.99 \\
$\mathrm{SO}_{3}$ & 2.62 \\
$\mathrm{LOI}$ & 4.20 \\
free CaO & 0.82 \\
compressive strength $[\mathrm{MPa}]$ & 19.45 \\
specific gravity $\left[\mathrm{g} / \mathrm{cm}^{3}\right]$ & 3.12
\end{tabular}

In all mixes, cement, and water content were kept constant. Proportions of all concrete ingredients used are given in Table II. The limonite (LIM), siderite (SID) and barite (BAR) aggregate concretes under investigation have density of $2600 \mathrm{~kg} / \mathrm{m}^{3}, 2953 \mathrm{~kg} / \mathrm{m}^{3}$, and $3414 \mathrm{~kg} / \mathrm{m}^{3}$, respectively.

\subsection{Gamma ray transmission test}

Shielding properties of heavyweight concrete has been tested produced with different heavyweight aggregate. Measurements have been carried out using a $\gamma$-ray sources ${ }^{60} \mathrm{Co}$ with two lines $E_{1}=1.17 \mathrm{MeV}$ and $E_{2}=$ $1.33 \mathrm{MeV}$ and $3^{\prime \prime} \times 3^{\prime \prime} \mathrm{NaI}(\mathrm{Tl})$ detector system. The amplified signal from the detector is recorded by a $16 \mathrm{k}$
TABLE II

Amounts of compositions of concretes in $1 \mathrm{~m}^{3}$.

\begin{tabular}{c|c|c|c|c|c}
\hline \hline Concrete & $\begin{array}{c}\text { Water } \\
{[\mathrm{kg}]}\end{array}$ & $\begin{array}{c}\text { Cement } \\
{[\mathrm{kg}]}\end{array}$ & $\begin{array}{c}\text { Fine } \\
\text { aggregate } \\
{[\mathrm{kg}]}\end{array}$ & $\begin{array}{c}\text { Coarse } \\
\text { aggregate } \\
{[\mathrm{kg}]}\end{array}$ & $\begin{array}{c}\text { Density } \\
{\left[\mathrm{kg} / \mathrm{m}^{3}\right]}\end{array}$ \\
\hline LIM & 184 & 366 & 1090 & 1635 & 2600 \\
SID & 184 & 366 & 1036 & 1553 & 2953 \\
BAR & 184 & 366 & 1090 & 1635 & 3414
\end{tabular}

channel multi-channel-analyzer (MCA) which communicates with the PC by Genie 2000 software. The schematic view of the experimental setup is shown in Fig. 1 [8].

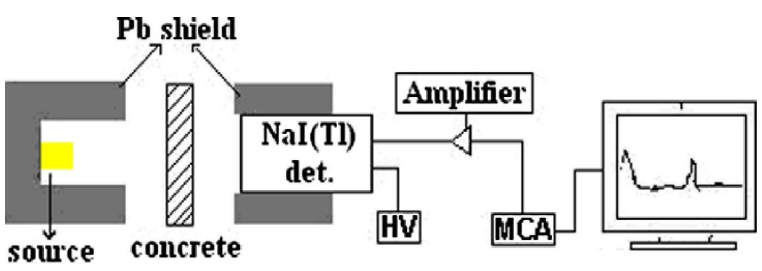

Fig. 1. Schematic diagram for test arrangement.

$10 \times 10 \times 50 \mathrm{~cm}^{3}$ prisms concrete samples that were of all different aggregates types were prepared. The later samples were cut in $5 \mathrm{~cm}$ thickness for measurements.

\section{Results and discussion}

Theory of gamma transmission — for narrow beam gamma ray attenuation is expressed by equation

$$
\frac{I}{I_{0}}=\mathrm{e}^{-\mu x}
$$

where $I_{0}$ is the initial gamma ray intensity $\left(\gamma /\left(\mathrm{cm}^{2} \mathrm{~s}\right)\right)$, $I$ is intensity after passing through a thickness $x$ of absorber $\left(\gamma /\left(\mathrm{cm}^{2} \mathrm{~s}\right)\right), x$ is absorber thickness $(\mathrm{cm})$ and $\mu$ is linear attenuation coefficient $\left(\mathrm{cm}^{-1}\right)$. I values of concretes was calculated by software of Genie2000 [9]. The linear attenuation coefficients of different types of heavyweight aggregate have been displayed in Fig. 2 as a function of gamma energies.

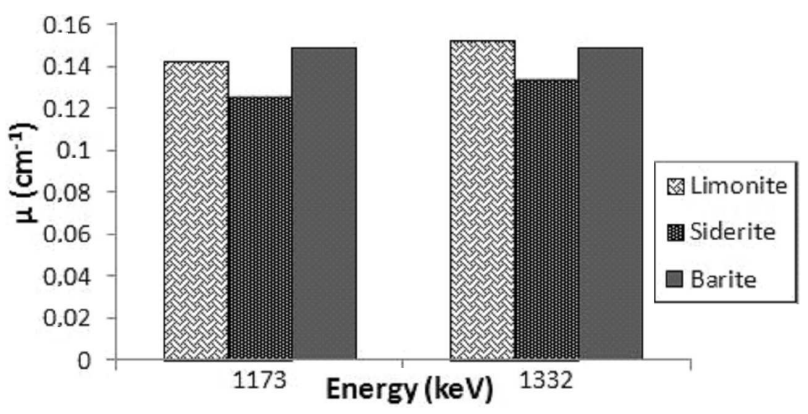

Fig. 2. Linear attenuation coefficient of concretes.

The thickness of any given material where $50 \%$ of the incident energy has been attenuated is known as the HVL 
(HVL is expressed in units of distance $(\mathrm{cm})$ ). A half value of layer of shielding material, $(X)_{1 / 2}$ defined at $I=\frac{I_{0}}{2}$, is given as:

$$
X_{1 / 2}=\frac{0.693}{\mu} \text {. }
$$

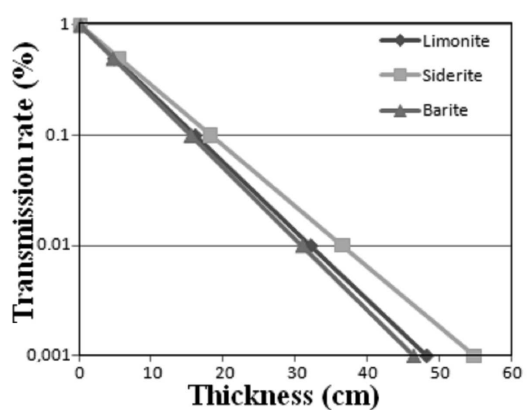

Fig. 3. Transmission rate of the heavyweight aggregate.

The effectiveness of gamma-ray shielding is described in terms of the HVL or the tenth value layer (TVL) of a material. The HVL is the thickness at which an absorber will reduce the radiation to half, and the TVL is the thickness at which an absorber will reduce the $\gamma$ -radiation to one tenth of its original intensity [8]. It is indicated that the attenuation coefficient and half value layer is a useful parameter for radiation shielding. As known, while the linear attenuation coefficients and half value layer thickness of barite and ordinary concrete are available in the literature, but the different heavy aggregate concretes' are not available in the literature. The transmission rate of the heavyweight aggregate as a function of material's thickness have been displayed in Fig. 3 where it is clearly seen that thicker siderite is required to stop gamma rays than other materials.

\section{References}

[1] R.L. Walker, M. Grotenhuis, "A summary of shielding constants for concrete", ANL-6443 Reactor Technology (TID-4500, 16th Ed., Amended), AEC Research and Development Report, 1961.

[2] Y.K. Lim, Korean Nucl. Soc. 2, 149 (1970).

[3] A.A. El-Sayed, Ann. Nucl. Energy 29, 1977 (2002).

[4] Structural Shielding Design and Evaluation for Megavoltage X-and Gamma-Ray Radiotherapy Facilities, Vol. 151, National Council on Radiation Protection and Measurement, Bethesda 2005.

[5] I.I. Bashter, A.E. Abdo, A.S. Makarious, Ann. Nucl. Energy 23, 1189 (1996).

[6] M.O. Aksi, Ph.D. Thesis, Department of Metallurgical and Materials Engineering, Middle East Technical University, 2004.

[7] F. Demir, G. Budak, R. Sahin, A. Karabulut, M. Oltulu, K. Şerifoğlu, A. Un, Ann. Nucl. Energy 37, 339 (2010).

[8] I. Akkurt, H. Akyıldırım, B. Mavi, S. Kilincarslan, C. Basyigit, Ann. Nucl. Energy 37, 910 (2010).

[9] I. Akkurt, C. Basyigit, S. Kilincarslan, B. Mavi, A. Akkurt, Cem. Concr. Comp. 28, 153 (2006). 